\title{
Screening of Hemoglobin disorder in non-endemic region
}

Hemoglobinopathies are group of inherited disorders which can broadly be classified into qualitative and quantitative defects. Qualitative defects include Sickle cell anemia whereas quantitative defect includes Thalassemia. Sickle cell anemia is characterised by abnormality in the structure of haemoglobin in particular substitution of adenine in sixth codon of $\beta$ gene (GAG-GTG), thereby encoding valine instead of glutamic acid in sixth position of $\beta$ chain. ${ }^{1}$ In thalassemia there is reduced production of one or more globin chains. Thalassemia is generally classified into two broad categories: $\alpha$-thalassemia and $\beta$-thalassemia usually caused by deletions of one or all four alleles of $\alpha$ - genes and point mutation $\beta$ gene respectively. This results in reduction or absence in globin chain synthesis. Hemoglobinopathies can be either in trait or disease condition. People with traits do not require medical or follow-up care after the initial diagnosis is made. People with $\beta$-thalassemia trait should be warned that their condition can be misdiagnosed as the more common iron deficiency anemia and should avoid routine use of iron supplements. Counselling is indicated in all persons with genetic disorders, especially when the family is at risk of a severe form of disease that may be prevented.

In Nepal, though actual data is not available, increased incidence of hemoglobinopathies is observed among the ethnic community of Terai region. As we know, inherited haemoglobin disorders (sickle-cell disorders and thalassaemias) were originally characteristic of the tropics and subtropics. However, due to migration it has become common worldwide. ${ }^{2-5}$ In Nepal; hemoglobinopathies are seen in other population than from Terai. Hemoglobinopathies can be controlled cost-effectively by programmes that integrate treatment with carrier detection and genetic counselling, WHO has recommended global development of these services. ${ }^{5}$

A policy of detecting carriers and informing them of their risk, and possibilities for reducing it, usually leads to a fall in births and deaths of affected children. Requirements are the same for thalassaemias and sickle-cell disorders. To prevent and minimize the disease regular screening; in all the communities; should be conducted at least in anaemic individuals with microcytic hypochromic anaema. Population screening is not the only useful strategy: family studies can be cost-effective.

The effects of screening depend on the choices made by informed individuals. Birth prevalence of thalassaemia can fall by over $90 \% 0^{6,7}$ because most at-risk couples limit their family to two healthy children, ${ }^{6.7}$ there is very high uptake of prenatal diagnosis, and some carriers avoid risk by selecting a non-carrier partner. ${ }^{67}$ Available data for sickle-cell disorders shows lower use of prenatal diagnosis8 and improved survival of affected children with neonatal diagnosis.

Dr. Shiva Raj KC, MBBS, MD

Associate Professor, Department of Pathology Kist Medical College Teaching Hospital, Imadole, Lalitpur

\section{Reference:}

1. Shrestha A, Karki S. Analysis of sickle haemoglobin. Journal of Pathology of Nepal 2013;3:437-40.

2. Livingstone FB. Abnormal hemoglobins in human populations. Chicago: Aldine; 1967.

3. Livingstone FB. Frequencies of hemoglobin variants. New York and Oxford: Oxford University Press; 1985.

4. Weatherall DJ, Clegg JB. Distribution and population genetics of the thalassaemias. 4th ed. Oxford: Blackwell Science; 2001. Chapter 6

5. Weatherall DJ, Clegg JB. Inherited haemoglobin disorders: an increasing global health problem. Bull World Health Organ 2001; 79: 704-12

6. Petrou M, Modell B, Shetty S, Khan M, Ward RH. Long-term effects of prospective detection of high genetic risk on couples' reproductive life: data for thalassaemia. Prenat Diagn 2000; 20: 469-74

7. Angastiniotis MA, Hadjiminas MG. Prevention of thalassaemia in Cyprus. Lancet1981; 1:369-71 